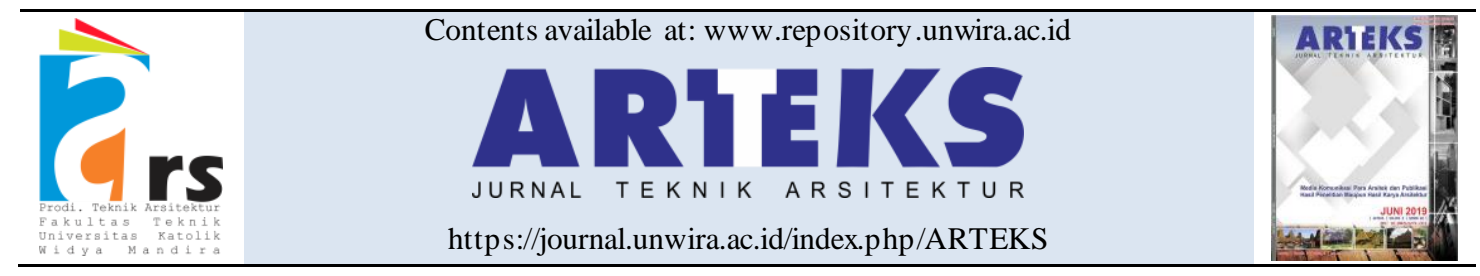

Research paper

doi: 10.30822/arteks.v6i1.620

\title{
Factors influencing personalization of dwellings among residents of selected public housing estates Lagos Nigeria
}

\section{Kolawole Opeyemi Morakinyo}

Department of Architecture Technology, School of Environmental Studies,

The Federal Polytechnic, Ede, Osun State, Nigeria

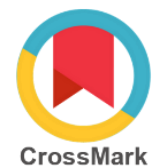

\begin{tabular}{|c|c|}
\hline ARTICLE INFO & ABSTRACT \\
\hline $\begin{array}{l}\text { Article history: } \\
\text { Received July 12, } 2020 \\
\text { Received in revised form August 12, } \\
2020 \\
\text { Accepted November } 19,2020 \\
\text { Available online April } 01,2021 \\
\text { Keywords: } \\
\text { Dwellings } \\
\text { Lagos Nigeria } \\
\text { Personalization of dwellings } \\
\text { Public housing }\end{array}$ & 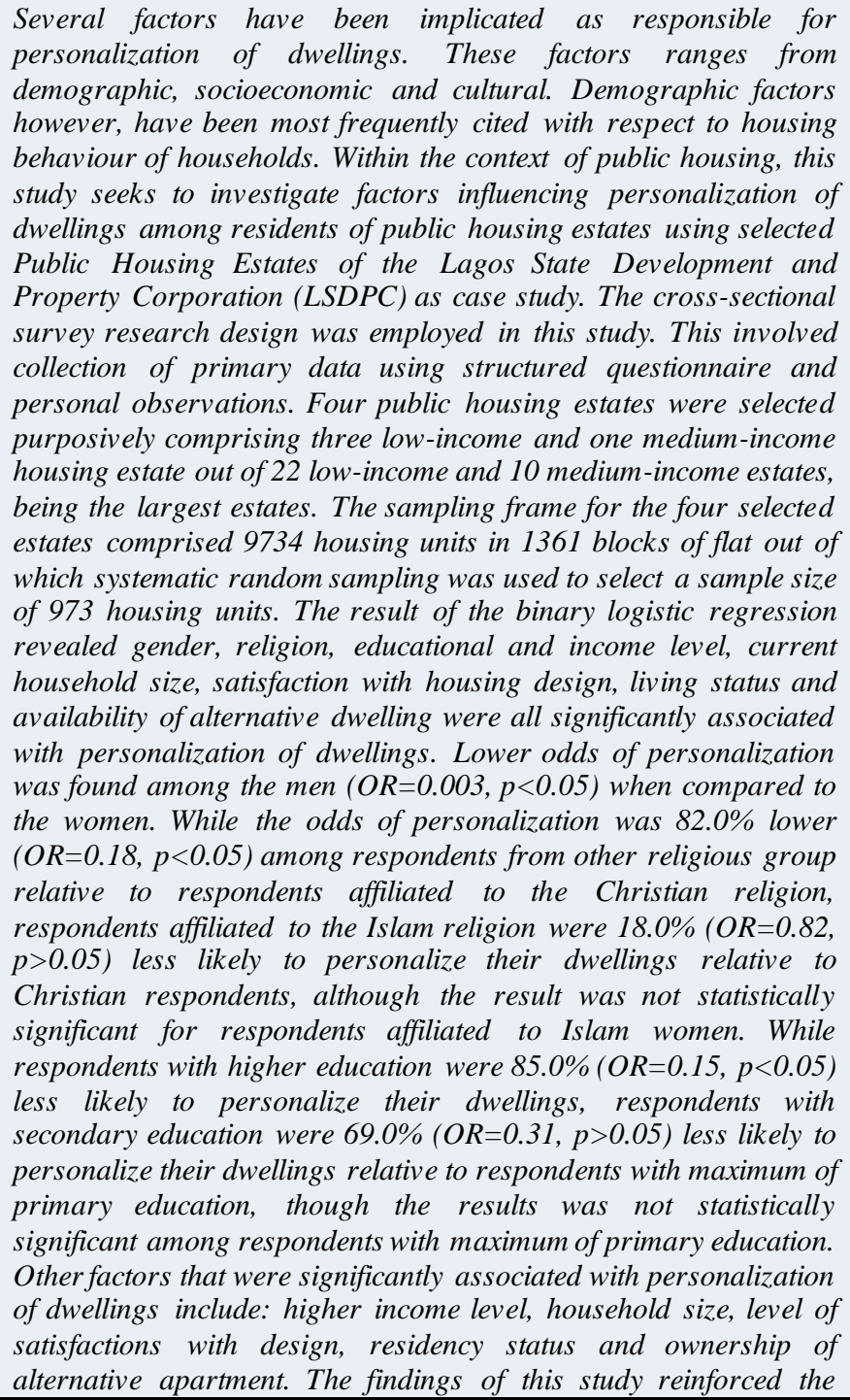 \\
\hline
\end{tabular}




\section{Introduction}

Housing embraces the totality of residential neighbourhood and environment comprising of physical structures, facilities and all other needed services that guarantees the health and social wellbeing of individuals and family (Salau, Opara-Nadi, and Swennen 1992). Furthermore, it symbolizes the status of an individual and describes one's personality as defined by the society (Adetunji Babatunde and Egwaikhide 2010). However, deviation in the expected role of housing as perceived by the occupants often results in modification and personalization of such house. The concept of pers onalization refers to the use of visible marker to define personal identity, create boundaries with aim of regulating the level of communications and social interactions among residents (Kopec 2006). The need for dwellings personalization arose from the desire of people to mark and distinguish their house from others. In other words, people personalize their dwellings by modifying the physical environment in a distinct way that reflects ownership (Abu-Ghazzeh 2000; Marcus and Sarkissian 1988).

Several factors have been implicated as responsible for personalization of dwellings. These factors ranges from demographic, socioeconomic and cultural. Demographic factors however, have been most frequently cited with respect to housing behaviour of households. For instance, changes in the size of the household has often been as sociated with changes in space need. The varying household size is a key factor that encourages occupants to personalize their dwellings because majority of these houses were not designed to meet the individual needs of the family.

Improved finance of the owners is also a major factor that affects the nature and extent of the post-constructional changes in these housing estates. It is common to find changes taking place when the financial capability of the house owner improves which could be as a result of either a promotion, increase in salary or inheritance. Whichever the case is it simply means that when house owners have more money to spend, they are most likely going to try to improve their house.

Within the context of public housing, this study seeks to investigate factors influencing personalization of dwellings among residents of public housing estates using selected Public Housing Estates of the Lagos State Development and Property Corporation (LSDPC) as case study.

The National Housing Policy (2012) defined housing as the process whereby secure, comfortable, attractive, functional, affordable and identifiable shelter in a suitable setting within a neighbourhood and supported by continuous maintenance of the built environment for daily living activities of individuals and families is provided while also putting into consideration their socioeconomic, cultural desires and preferences. Similarly, Abdul Karim (2008) argues that housing consist of both physical and social components. The physical components include the house, facilities and utilities, while the social components comprises of the individuals occupying the house, neighbours and the community. When houses failed to perform the required function, the resultant effect is that people tends to engage in personalization.

The process of personalization of dwellings have been found to be very important to occupants because the entire process ultimately aim to create a place that can be called home. Through personalization, occupants can modify their dwelling to suit their taste (Gifford 1997; Ressell, Potangaroa, and Feng 2008). Moreover, studies have identified personalization of dwellings to be influenced by several factors ranging from socio- 
demographic such as gender and religion, cultural reasons, level of satisfaction, need for privacy, identify among others. For instance, Sazally et al. (2012) in their study assessing personalization of houses in terraced houses in Malaysia identified the absence of mutual respect and respect to cultural values and rites as two key factors responsible for personalization of terraced houses (Sazally et al. 2012).

Gender consideration have been identified by Tognoli (1980) as factor in personalization of dwellings (Tognoli 1980). According to this study which investigated gender differences with respect to their feelings towards domestic space, the author revealed both men and women demonstrated high level of sensitivity to their living space. For instance, it was found that while the women were able to recollect most of the events that occurred over the past week in their rooms, the men on the other hand were more concerned about the design and decoration in their kitchen and bathroom.

Religious convictions have also been identified as one of the driver of dwellings personalization. Weibel and Weisner (1981) in their submission argued that values and ideologies has a way of influencing home environment especially where religious differences or strong ideological convictions are held with utmost importance (Weisner and Weibel 1981). Others have reported the need to reflect personality and lifestyle as a basis for personalization of dwellings. These studies suggest that people personalize their dwellings to give it meaning i.e. personalization of dwellings is use to express and showcase the level of emotional ties with other existing environment (Marcus and Sarkissian 1988). Similarly, personalization of dwellings is reported to occur as a means of reflecting one's interest, abilities, personality and value. As such, the various elements used in the process becomes signs by which observers form their impressions about the occupants of the dwelling. These impressions is now the yardstick for drawing inferences about the personality of the occupants (Gosling et al. 2002; Gosling et al. 2005).

House owners also personalize their dwellings for financial benefits in addition to other needs from which they derive satisfaction. Improved finance of the owners is a major factor that affects the nature and extent of the post-constructional changes in these housing estates. It is common to find changes taking place when the financial capability of the house owner improves which could be as a result of either a promotion, increase in salary or inheritance. Whichever the case is it simply means that when house owners have more money to spend they are most likely going to try to improve their house. Also, dwellers respond to increased demand for space due to the expansion of household size, the inevitable increase in family size due procreation and extended family ties have also been cited as a motivation to carryout personalization. The need to create more rooms or enlarge existing ones to accommodate family members came as a pressing challenge which was tackled through what they considered to be most affordable when compared with other option opened to them. Most times, their sizes were quite small as at the time they moved in, compared to what happened years after or even their present sizes.

On the otherhand, Natakun \& O'Brien (2008) in their study conducted in Bangkok which investigated modifications to government-built houses in the metropolitan area of the region of the country revealed people resort to such modifications because of the simplicity of the buildings and the inability of the buildings to meet their needs (Natakun and O'Brien 2008). However, this assumption might not be completely right when examined in the order stated because it suggest that if the houses were not simple, modification will not occur. It is therefore, the different individual needs that were responsible for user-initiated modification. Overall, the authors identified four categories of modification carried out by the occupants of these buildings namely: extension of the size of the fence, replacing the earth with paving, enlargement of the indoor spaces and addition of decorations.

Similar to findings from Natakun \& O'Brien, Adebayo (2011) in a study of mass housing in Kwara state, Nigeria, highlighted three key categories of modifications carried out by occupants as: physical changes, changes in decoration and space conversion (Adedayo 2011). Explaining further, the first category of modification which is physical changes involved changes in relation to the structure of the building such as type of window and size, extension of the building envelop, provision of pre-sit areas, relocation of doors and making provision for lobbies. Changes made with respect to decoration were more of aesthetics in nature, while changes made with respect to space conversion include: conversion of courtyards to bedrooms, dinning 
space to bedrooms and conversion of stores to toilets. These changes suggest these conversion might be informed by increased family size. Although, this study showed that all of these changed made to the apartment were carried out by house owners and not tenants and these changes were found to have permanent impact on the physical appearance of the housing pattern. It was therefore concluded that these changes where done because it was considered right by the occupants and also as a means of expressing their personality.

\section{Method}

The study area: Lagos State

This study is conducted in Lagos, Southwest Nigeria between latitude $6^{\circ}$ and $7^{\circ}$ North of the equator, and longitude $3^{\circ}$ and $4^{\circ}$ east of the Greenwich Meridian. In terms of size, Lagos state is one of the smallest states in Nigeria $\left(3,577 \mathrm{~km}^{2}\right)$ but home to largest population in Nigeria with people from different ethnic background living in the state. With a population over 16 million, Lagos is regarded as the seventh fastest growing city in the world, and the second largest city in Africa (Dano et al. 2020). People from different ethnic and socio-cultural background resides in this city as a result of rural-urban migration which has significantly aided the rapid population growth. Important districts include: the old city, (now the commercial district) on western Lagos Island, Ikoyi Island, situated just east of Lagos Island, Apapa, (the chief port district) on the mainland, low-lying Victoria Island, industrialized Iddo Island and a group of mainland suburbs, Ebute Metta, Yaba, Surulere, Mushin, and Ikeja, while places like Alimosho, Abule-Egba, Lagbado have further enlarged the residential, commercial and administrative landmass of Lagos State.

Official intervention in housing provision in Nigeria began with the creation of the Lagos Executive Development Board (LEDB) in 1928 to tackle the housing-related bubonic plague and rid Lagos of the filth and unhealthy living and housing conditions that existed. Since then, government's direct involvement in housing development and delivery has increased (Makinde 2015; Jiboye 2011). As part of their efforts to reduce the problem of housing shortage in Lagos, the Federal and Lagos state governments embarked on housing development for different categories of Nigerians residing within the Metropolitan Area. However, the direct impact of the Federal government was not felt in housing provision for the masses in Lagos until 1973 when it established the Federal Housing Authority. This was subsequently followed by the creation of the Federal Ministry of Housing, Urban Development and Environment. Today, quite a good number of public housing schemes developed by both the Federal and State governments exist in virtually every major location within Lagos.

Specifically, the study context comprises four selected estates in which the study was conducted. A preliminary survey was used to purposively select the four estates from the 20 low and 10 medium-income public housing Estates in Lagos State. The selected four (4) LSDPC public housing estates in Lagos metropolis are: Abesan, Iponri, Is olo, Ijaiye, public housing estates. These estates have been observed to exhibit a preponderance of indicators of personalization in forms of physical, spatial and façade changes, extension and addition of extra units, change of use and function. These were estates also among those that have been inhabited over a long period of time. The selected estates were:

1. Abesan Low-Income Housing Estate, Ipaja;

2. Iponri Low Income Housing Estate;

3. Isolo Low-Income Housing Estate;

4. Ijaiye Medium-Income Housing Estate.

These brief descriptions of each estate were from the researcher's personal observation and existing records on the estates. This was done in order to provide background information on the physical and other characteristics of the selected housing estates.

\section{Data source}

The data for this study were obtained from both primary and secondary sources. The study utilized a survey research design, in which primary data were collected using structured questionnaire and personal observations. Purposive sampling technique was used to select four public housing estates comprising three lowincome and one medium-income housing estate out of 22 low-income and 10 medium-income estates, being the largest estates. The sampling frame for the four selected es tates comprised 9734 housing units in 1361 blocks of flat out of which systematic random sampling was used to select a sample size of 973 housing units. Secondary data 
were obtained from neighbourhood plans, architectural drawings of housing typologies, and the estate master plans.

Study population and sampling technique

Using Income criterion, two categories of housing, representing two income levels, were identifiable and selected for the study. They consist of low-income and medium-income housing estates. These patterns and categories are peculiar and similar to those available in public housing development in Nigeria, generally. They also provide useful anecdotes or examples to support more generalized statistical findings. These estates were carefully selected through a preliminary field survey method to demonstrate the complexities of the worldwide phenomenon amongst a number of public housing Estates in Lagos. They effectively represent residents' personalization as it occurs in public housing schemes in Nigeria.

Data analysis

Background characteristics of respondents

Table 1 shows the distribution of respondents according to their background characteristics. Distribution according to sex revealed more males (83.2\%) than females (16.8\%) across all the selected public housing estates. Age group distribution indicates $(40.7 \%)$ of respondents were in the age group 41-50 years across, followed by (28.9\%) of respondents in the age group 31-40 years, while respondents in age group 21-30 years $(0.3 \%)$ were least represented across all the selected housing estates. Overall, the results indicates more youthful household heads with the largest being the age group between 41 and 50 years. This pattern of age distribution may have an impact on the vibrancy and kinds of activities that might be taking place within these estates. On the other hand a young age group could suggest more personalization is expected in the future considering the stage in the life cycle.

The presentation of respondents according to marital status revealed more than two thirds of the total respondents from all the selected housing estates were married, followed by respondents who are widower, accounting for $(9.6 \%)$ and widow (9.4\%) of the total respondents. Respondents who are divorced accounted for the least proportion $(0.2 \%)$. The distribution of respondents according to ethnicity indicates the predominance of the Yoruba ethnic group across all the selected housing estates. The fact that about two thirds $(64.0 \%)$ of respondents were from the Yoruba ethnic group can be attributed to the fact that this study was conducted in southwest Nigeria, predominantly occupied by people from the Yoruba ethnic group. This was followed by the Igbo ethnic group, accounting for $(29.2 \%)$, respondents from the Hausa ethnic group accounted for the least proportion (6.8\%).

The distribution of respondents according to religious affiliation revealed that $(71.0 \%)$ of respondents across all the selected housing estates, were Christians, followed by respondents who practiced Islam, accounting for one quarter $(25.1 \%)$ of the total respondents across all the selected housing estates. Furthermore, educational background and the academic qualification of respondents, affect the choices that residents of a house make on housing. A more educated resident is expected to make moreinformed choices. The distribution of respondents according to educational attainment indicates approximately half $(49.9 \%)$ of the total respondents surveyed across the selected housing estates had vocational education, followed by first degree holders, accounting for $(30.4 \%)$, while those who possessed postgraduate degree accounted for $(17.1 \%)$ of the total respondents surveyed. The distribution of respondents according to income category revealed more than half $(55.5 \%)$ across all the selected housing estates belonged to the middle-income group, followed by respondents belonging to the highincome group (26.6\%), while respondents from the low-income group accounted for the least proportion $(17.9 \%)$ of the total respondents. The result of the analysis also showed more than half $(54.0 \%)$ have spent between 2-3 years in their apartment, with over three quarter $(88.3 \%)$ admitting they will live in their present apartment for as long as possible. Block of flat constitute majority $(99.8 \%)$ of the building type, while majority (44.7\%) were previously living in a single dwelling before moving into the housing estate.

Table 1. Socio-demographic characteristics of respondents

\begin{tabular}{lccccc}
\hline Variables & \multicolumn{5}{c}{ Selected housing estates } \\
\hline Sex & Abesan & Iponri & Isolo & Ijaiye & Total \\
& LIH & LIH & LIH & MIH & \\
\hline Male & 340 & 77 & 277 & 69 & 769 \\
& $(81.9)$ & $(82.8)$ & $(83.9)$ & $(87.3)$ & $(83.2)$ \\
\hline Female & 75 & 16 & 53 & 10 & 154 \\
& $(18.1)$ & $(17.2)$ & $(16.1)$ & $(12.7)$ & $(16.8)$ \\
\hline
\end{tabular}




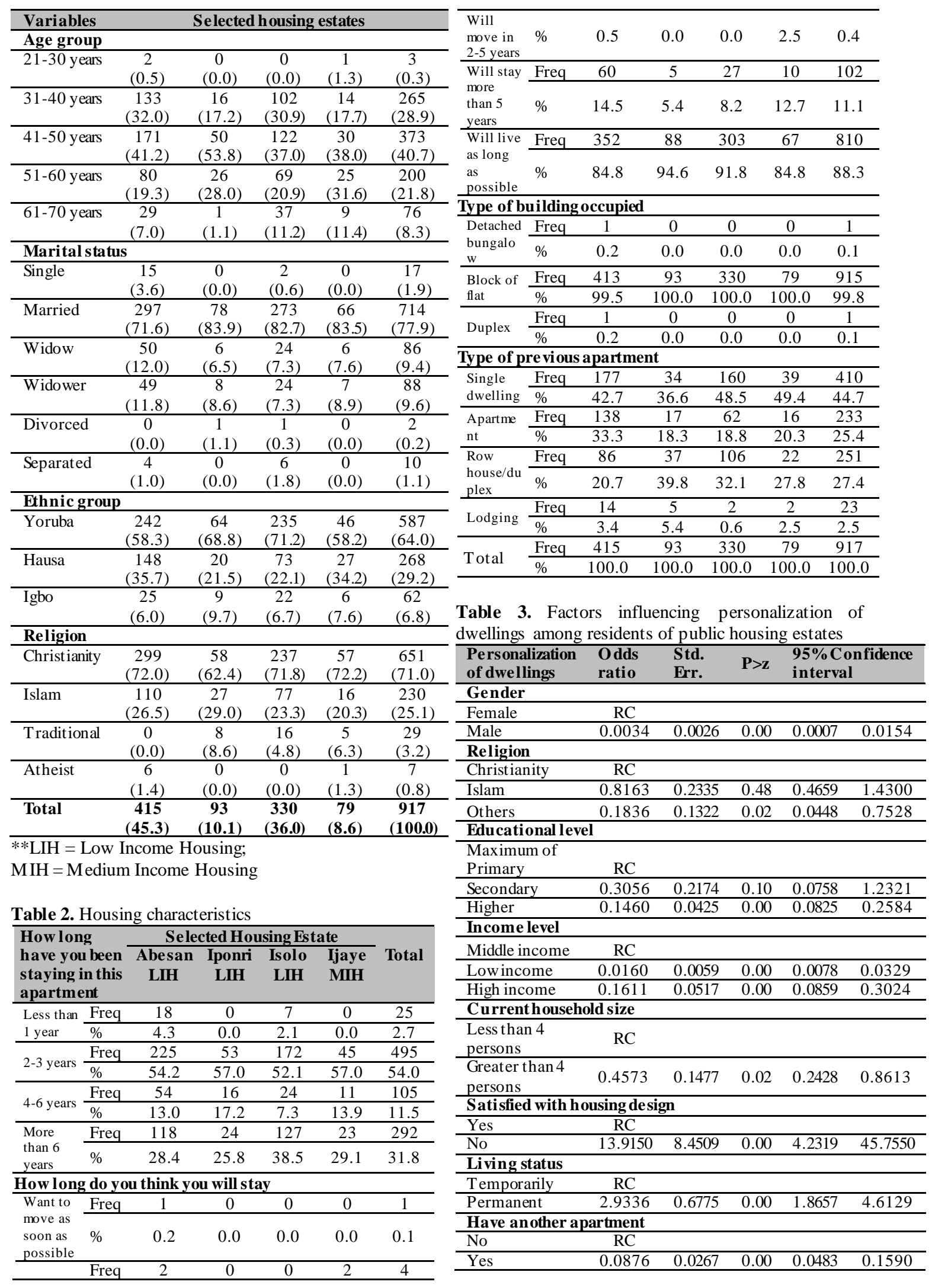




\begin{tabular}{|c|c|c|c|c|}
\hline $\begin{array}{l}\text { Personalization } \\
\text { of dwellings }\end{array}$ & $\begin{array}{l}\text { Odds } \\
\text { ratio }\end{array}$ & $\begin{array}{l}\text { Std. } \\
\text { Err. }\end{array}$ & $\mathbf{P}>\mathbf{z}$ & $\begin{array}{l}95 \% \text { Confide } \\
\text { interval }\end{array}$ \\
\hline $\begin{array}{l}\text { Statistics: Pseud } \\
=580.62\end{array}$ & $\mathrm{R}^{2}=0.4$ & $\mathrm{Pmb}$ & & $01 \mathrm{LR} \mathrm{chi}^{2}(11)$ \\
\hline
\end{tabular}

\section{Result and discussion}

Factors influencing personalization of dwellings

Factors influencing personalization of dwellings in the study area was examined using binary logistic regression. The choice of binary logistic regression was informed by the categorical nature of the outcome variable i.e. whether the occupants have at one time or the other changed or modified their building to meet their needs. The result of the binary logistic regression revealed gender, religion, educational and income level, current household size, satisfaction with housing design, living status and availability of alternative dwelling were all significantly associated with personalization of dwellings.

Lower odds of personalization was found among the men $(\mathrm{OR}=0.003, \mathrm{p}<0.05)$ when compared to the women. Findings from similar study by Wells (2000) revealed the intention to personalize often differ by sex and that personalization among women is generally a means of expressing identity and improve their feelings (Wells, Thelen, and Ruark 2007). On the other hand, personalization among men was seen as a way of expressing their status. Jones et al (2007) also investigated preferred bedroom contents for eighth and ninth grade adolescents (13 to 15 age range) (Jones et al. 2007). They found that girls and boys differed on their bedroom design preferences. Boys preferred more of masculine designs, sports related items, and things they could build. The boys were also not very involved in designing their bedrooms. The girls had a mixture of both feminine and masculine items such as pictures, stuffed animals, chess board games, vanity dressing tables, makeup/hair accessories, floral designs as they were not constrained by traditional gender boundaries. While odds of personalization was $82.0 \%$ lower $\quad(\mathrm{OR}=0.18, \quad \mathrm{p}<0.05)$ among respondents from other religious group relative to respondents affiliated to the Christian religion, respondents affiliated to the Islam religion were $18.0 \% \quad(\mathrm{OR}=0.82, \quad \mathrm{p}>0.05)$ less likely to personalize their dwellings relative to Christian respondents, although the result was not netatistically significant for respondents affiliated to-Islam women. There was a decreased odd of personalization of dwellings with increasing education. While respondents with higher education were $85.0 \% \quad(\mathrm{OR}=0.15, \mathrm{p}<0.05)$ less likely to personalize their dwellings, respondents with secondary education were $69.0 \% \quad(\mathrm{OR}=0.31$, $\mathrm{p}>0.05$ ) less likely to personalize their dwellings relative to respondents with maximum of primary education, though the results was not statistically significant among respondents with maximum of primary education.

Furthermore, higher income level was as sociated with lower odds of personalization of dwellings, respondents in the lower and high income level were $98.0 \%(\mathrm{OR}=0.02, \mathrm{p}<0.05)$ and $84.0 \%$ less likely to personalize their dwelling when compared to respondents in the middle income level, while respondents with more than four persons in the household were $54.0 \%(\mathrm{OR}=$ $0.46, p<0.05$ ) less likely to personalize relative to household with less than four persons. Finally, respondents not satisfied with housing design $(\mathrm{OR}=13.9, \quad \mathrm{p}<0.05)$, are permanent residents $(\mathrm{OR}=2.93, \mathrm{p}<0.05)$ were multiple times more likely to personalize their dwellings relative to those satisfied and about three times more likely to personalize relative to respondents with temporary residence status, while lower odds of personalization of dwellings was found among respondents who have another apartment $(\mathrm{OR}=$ $0.09, \mathrm{p}<0.05)$ relative to respondents not having another apartment.

\section{Conclusion}

This study has investigated factors influencing personalization of dwellings among residents of public housing estates in Lagos, Nigeria. Sociodemographic and socioeconomic factors namely sex, educational level, income level, religion, current household size, satisfaction with building design, living status (temporary or permanent residence) and having alternative apartment were significantly associated with personalization of dwellings in the study area. The outcome of this study therefore underscores the importance of demographic and economic factors with respect to personalization of dwellings. 


\section{References}

Abu-Ghazzeh, Tawfiq M. 2000. 'Environmental Messages in Multiple-Family Housing: Territory and Personalization'. Landscape Research $25 \quad$ (1): 97-115. https://doi.org/10.1080/014263900113190.

Adedayo, O. F. 2011. 'Customization of Housing Units on Mass Housing Estates on Nigeria: A Case Study of Kwara State'. University of Technology Minna, Niger State.

Adetunji Babatunde, M., and Festus O. Egwaikhide. 2010. 'Explaining Nigeria's Import Demand Behaviour: A Bound Testing Approach'. International Journal of Development Issues 9 (2): 167-87. https://doi.org/10.1108/14468951011062354.

Dano, Umar Lawal, Abdul-Lateef Balogun, Is maila Rimi Abubakar, and Yusuf Adedoyin Aina. 2020. 'Transformative Urban Governance: Confronting Urbanization Challenges with Geospatial Technologies in Lagos, Nigeria'. GeoJournal 85 (4): 1039-56. https://doi.org/10.1007/s 10708-019-10009-1.

Gifford, Robert. 1997. Environmental Psychology: Principles and Practice. United States: Allyn \& Bacon.

Gosling, Samuel D., Kenneth H. Craik, Nicholas R. Martin, and Michelle R. Pryor. 2005. 'The Personal Living Space Cue Inventory'. Environment and Behavior 37 (5): 683-705. https://doi.org/10.1177/0013916504274011.

Gosling, Samuel D., Sei Jin Ko, Thomas Mannarelli, and Margaret E. Morris. 2002. 'A Room with a Cue: Personality Judgments Based on Offices and Bedrooms.' Journal of Personality and Social Psychology 82 (3): 379-98. https://doi.org/10.1037/00223514.82.3.379.

Jiboye, Adesoji David. 2011. 'Evaluating Public Housing Performance: Providing a Basis for Residential Quality Improvement in Nigeria'. Middle-East Journal of Scientific Research 9 (2): 225-32.

Jones, Randall M., Denise E. Taylor, Andrew J. Dick, and Archana Singh. 2007. 'Bedroom Design and Decoration: Gender Difference in Preference and Activity'. Adolescence 42 (167): 539-53.

Kopec. 2006. Environmental Psychology for Design. Fairchild s, Hardcover.

Makinde, Olusola Oladapo. 2015. 'Influences of Socio-Cultural Experiences on Residents'
Satisfaction in Ikorodu Low-Cost Housing Estate, Lagos State'. Environment, Development and Sustainability 17 (1): 17398. https://doi.org/10.1007/s 10668-014-95456.

Marcus, Clare Cooper, and Wendy Sarkissian. 1988. Housing As If People Mattered: Site Design Guidelines for Medium-Density Family Housing. 1st ed. California: University of California Press.

Natakun, Boonanan, and David O'Brien. 2008. 'Extending the House/ Extending the Dream: Modification to Government-Built Housing in Bangkok Metropolitan Regional'. Journal of Architectural Planning Research and Studies 6 (3): 45-64. https://so02.tcithaijo.org/index.php/jars/article/view/168717 /121386.

Ressell, A., R. Potangaroa, and V. Feng. 2008. 'Houses or Homes? The Patterns of Design'. In The 4th International Post Disaster Reconstruction Conference, $i$ - Rec 2008. Christchurch, New Zealand: i - Rec.

Salau, O.A., O.A. Opara-Nadi, and R. Swennen. 1992. 'Effects of Mulching on Soil Properties, Growth and Yield of Plantain on a Tropical Ultisol in Southeastern Nigeria'. Soil and Tillage Research 23 (1-2): 73-93. https://doi.org/10.1016/0167-1987(92)90006W.

Sazally, Salehaton H., Erdayu Os'Hara Omar, Hazlina Hamdan, and Anniz Fazli Ibrahim Bajunid. 2012. 'Personalisation of Terraced Houses in Section 7, Shah Alam, Selangor'. Procedia - Social and Behavioral Sciences 49: 319-27. https://doi.org/10.1016/j.sbspro.2012.07.030.

Tognoli, Jerome. 1980. 'Differences in Women's and Men's Responses to Domestic Space'. Sex Roles $6 \quad$ (6): $\quad 833-42$. https://doi.org/10.1007/BF00287238.

Weisner, Thomas S., and Joan C. Weibel. 1981. 'Home Environments and Family Lifestyles in California'. Environment and Behavior 13 (4): 417-60. https://doi.org/10.1177/0013916581134002.

Wells, Meredith M., Luke Thelen, and Jennifer Ruark. 2007. 'Workspace Personalization and Organizational Culture'. Environment and Behavior $39 \quad$ (5): 616-34. https://doi.org/10.1177/0013916506295602. 